Article

\title{
Evaluation of blood electrolyte alterations in cats during elec- tive laparoscopic ovariectomy
}

\author{
Iulia Melega ${ }^{1 *}$, Lucia Victoria Bel ${ }^{1}$, Cosmina Andreea Dejescu ${ }^{1}$, Mădălina Florina Dragomir ${ }^{1}$, Bogdan Sevastre $^{1}$, Liviu \\ Ioan Oana ${ }^{1}$, Cosmin Petru Peștean ${ }^{1+}$ \\ 1 University of Agricultural Sciences and Veterinary Medicine of Cluj-Napoca, Romania \\ * Correspondence: iulia.melega@usamvcluj.ro \\ + Same contribution as the first author
}

\begin{abstract}
In a clinical setting, we tested the hypothesis of whether hypercapnia developed during carbon dioxide pneumoperitoneum is associated with changes in blood electrolytes. This prospective study involved ten female cats that underwent elective laparoscopic ovariectomy. Venous blood samples for assessment of electrolytes were collected in the following sequence: T1- before anaesthesia induction, T2 - 10 minutes after anaesthesia induction, T3 - 30 minutes of pneumoperitoneum and T4 - at the end of pneumoperitoneum. Statistical analysis revealed $\mathrm{AB}$ disturbances associated with general anaesthesia and pneumoperitoneum, manifested with decreased blood $\mathrm{pH}$, whereas blood $\mathrm{PvCO}_{2}, \mathrm{PO}_{2}$ and $\mathrm{BE}$ were increased. A constant increase of $\mathrm{K}+$ concentration was recorded in all animals during pneumoperitoneum $(\mathrm{P}<0.05)$, whereas iMg registered a significant increase only at $\mathrm{T} 3(\mathrm{P}<0.05)$. Correlations were recorded between blood $\mathrm{pH}$ and $\mathrm{Na}+, \mathrm{iCa}, \mathrm{iMg}$, as well as between $\mathrm{Na}+$ and $\mathrm{Cl}^{-}$at different time points during anaesthesia. $\mathrm{No}$ correlations were noted between $\mathrm{pH}$ and $\mathrm{K}+$ or $\mathrm{PvCO}_{2}$ and $\mathrm{K}+$. In conclusion, electrolyte imbalance represents a possible complication associated with laparoscopic surgery in healthy cats. However, further studies should investigate the causes involved in $\mathrm{K}+\mathrm{concen}-$ tration elevation.
\end{abstract}

Keywords: hyperkalemia, pneumoperitoneum, laparoscopy, feline

Received: 17.08 .2021

Accepted: 30.08 .2021

Published: 09.09.2021

DOI: $10.52331 /$ cvj.v26i2.26

Copyright: (c) 2021 by the authors. Submitted for possible open access publication under the terms and conditions of the Creative Commons Attribution (CC BY) license (http://creativecommons.org/licenses/by/4.0/).

\section{Introduction}

Ovariectomy is the most common abdominal laparoscopic surgical procedure performed in small animals, which has gained popularity during the last decade [3]. The essential characteristic of laparoscopic surgery is represented by carbon dioxide $\left(\mathrm{CO}_{2}\right)$ insufflation inside the peritoneal cavity, to achieve surgical view and working space [8]. It has been postulated that these procedures are associated with lower morbidity, expedited recovery time and reduced postoperative pain. However, the pneumoperitoneum leads to increased abdominal pressure, which can further develop significant cardiovascular and respiratory changes, which represent a potential life-threatening condition [27][15].

Acid, base and electrolyte alterations are typically observed in the perioperative period, and are related to underlying conditions but may be also iatrogenic. General anaesthetics, intraoperative excessive tissue handling, the nature of fluids infused and metabolic derangements, have all been demonstrated to possess risks of inducing severe electrolyte imbalance [20]. In animal studies, laparoscopic surgery has been associated with alterations of acid-base $(\mathrm{AB})$ metabolism as a manifestation of respiratory acidosis. Gas insufflation into the abdominal cavity highly affects respiratory mechanics through a reduced lung volume due to diaphragmatic limited excursions, diminished functional residual capacity and respiratory compliance [15]. Altogether, these factors can affect 
the lung compensatory mechanism of $\mathrm{AB}$ balance regulation, resulting in hypercapnia [22]. Moreover, the diffusion of peritoneal $\mathrm{CO}_{2}$ into the bloodstream increases further the concentration of $\mathrm{CO}_{2}\left(\mathrm{PaCO}_{2}\right)$. This increase will ultimately lead to blood $\mathrm{pH}$ changes toward acidosis [28].

For optimal functioning of the cells, relative constancy of the body's $\mathrm{pH}$ is essential because metabolism requires enzymes that operate at fairly narrow limits of $\mathrm{pH}$. Electrolytes represent cofactors in enzymatically maintained metabolic reactions, playing vital roles in cellular function, tissue perfusion and $\mathrm{AB}$ balance [22]. Any changes of $\mathrm{pH}$ could disrupt cell metabolism and consequently body function.

Several studies showing the cardiopulmonary changes due to $\mathrm{CO}_{2}$ induced pneumoperitoneum have been reported previously in domestic cats, but such data regarding electrolytes homeostasis is lacking from the literature. Therefore, the objective of this study was to analyse selected electrolyte alterations in healthy feline patients undergoing laparoscopic ovariectomy, using an in-house blood gas analyser. Based on our current understandings, it was hypothesized that $\mathrm{AB}$ imbalance developed during laparoscopic surgery, even for a short period, can affect electrolyte balance.

\section{Materials and Methods}

In this prospective study, cats were enrolled for elective laparoscopic ovariectomy. Exclusion criteria included evidence of pregnancy and other abnormalities found on the physical examination. Surgical procedures were realized with the owner consent and the study was approved by the Comity for Bioethics and Research Ethics of University of Agricultural Sciences and Veterinary Medicine Cluj-Napoca (aut. No 211 from 27.05.2020). All video-assisted ovariectomies were performed by the same surgeon.

Food was withheld one night before surgery. The anaesthesia protocol for each feline patient consisted of premedication with $20 \mathrm{mcg} / \mathrm{kg}$ of Buprenorphine (Buprecare $0.3 \mathrm{mg} / \mathrm{ml}$, Recipharm Monts, UK) and 10 $\mathrm{mcg} / \mathrm{kg}$ of Medetomidine (Domitor $1 \mathrm{mg} / \mathrm{kg}$, Orion Corporation, Finland) by intramuscular administration. General anaesthesia was achieved by intravenous administration of $0.25 \mathrm{mg} / \mathrm{kg}$ Diazepam (Diazepam 5 $\mathrm{mg} / \mathrm{ml}$, Sun Pharma Company, Romania) and $3 \mathrm{mg} / \mathrm{kg}$ Ketamine (Narkamon Bio $100 \mathrm{mg} / \mathrm{ml}$, Bioveta, Czech Republic), and maintained with 1.5\% Isoflurane (Isoflutek 1000mg/g, Laboratorios Karizoo, Spain) in 100\% Oxygen $(1 \mathrm{~L} / \mathrm{min})$, using a rebreathing anaesthesia circuit (Dräger Medical, Germany). All animals received mechanical ventilation with a Dräger Fabius Plus XL anaesthetic machine (Dräger, Germany). Ventilator parameters were adjusted to deliver a tidal volume of $8-10 \mathrm{ml} / \mathrm{kg}$ at a respiratory rate to maintain an endtidal carbon dioxide tension (EtCO2) below $60 \mathrm{mmHg}$. Fluid therapy with $\mathrm{NaCl} 0.9 \%$ solution $(\mathrm{NaCl} 0.9 \%$ B Braun, Germany) was administered at a rate of $5 \mathrm{ml} / \mathrm{kg} /$ hour. A bolus of $6 \%$ hydroxyethylstarch $(6 \% \mathrm{Hem}-$ ohes 200/0.5, B Braun, Germany) of $2 \mathrm{ml} / \mathrm{kg}$ was administered over $2 \mathrm{~min}$ for patients with mean arterial pressure $(\mathrm{MAP})<60 \mathrm{mmHg}$. Upon completion of the procedure, the animals were placed in a recovery box. Meloxicam (Melovem $5 \mathrm{mg} / \mathrm{ml}$, Dopharma, Romania) $0.2 \mathrm{mg} / \mathrm{kg}$ subcutaneously was administered for complete analgesia.

Monitoring of anaesthesia during the study was performed by use of a multiparameter monitor (Vista 120, Dräger, Germany) and included electrocardiography (ECG) using a Lead II configuration, puls-oxymetry $\left(\mathrm{SpO}_{2}\right)$, body temperature and non-invasive blood pressure. A small volume of approximately $1 \mathrm{ml}$ of the venous blood sample was collected using a $2 \mathrm{ml}$ pre-heparinized syringe (Luer Slip Blood Gas Sampling system, Numbrecht Germany) from the jugular vein and analysed using a point-of-care blood gas analyser (Stat Profile Prime Plus ${ }^{\circledR}$ VET Critical Care Analyzer, Nova Biomedical). The blood was evaluated for $\mathrm{pH}$, $\mathrm{PvCO}_{2}$ (partial pressure of carbon dioxide), $\mathrm{PO}_{2}$ (partial pressure of oxygen), blood concentrations of sodium $(\mathrm{Na}+)$, potassium $(\mathrm{K}+)$, ionized calcium $(\mathrm{iCa})$, ionized magnesium $(\mathrm{iMg})$, chloride $(\mathrm{Cl}-)$, glucose $(\mathrm{Glu})$, base excess (BE), haematocrit $(\mathrm{Ht})$ and haemoglobin $(\mathrm{Hb})$, all parameters being integrated into the analyser panel. The measurements were performed after premedication (T1, baseline values), 10 minutes after induction of anaesthesia (T2, control), 30 minutes after the start of pneumoperitoneum (T3) and at the end of pneumoperitoneum (T4). A standard surgical procedure using a two-port approach was performed by the same surgeon. Insufflation pressure of $\mathrm{CO}_{2}$ was limited to $6 \mathrm{mmHg}$, consistent with previous clinical reports [25] 


\section{Statistical analysis}

All data are reported as the mean \pm SD. To assume Gaussian distribution normality distribution was checked by Shapiro-Wilk normally test. One-way analysis of variance ANOVA, followed by post hoc Tukey's range test procedure was done for pair-wise comparisons and Pearson test analyzed the correlation between normally distributed values. Pearson's correlation was used to assess the correlation between normally distributed variables; the interpretation was done according to Colton scale. Statistical significance was at $\mathrm{p}<0.05$ (95\% confidence interval). Statistical values and figures were obtained using GraphPad Prism version 5.0 for Windows, GraphPad Software, San Diego California USA.3.1. Subsection

\section{Results}

Measurement of electrolytes was successfully performed in ten healthy cats, American Society of Anaesthesiologists status 1 , with a mean age of 14.4 months (range 6-48 months, Standard deviation (SD) \pm 12.92 ) and body weight $2.64 \mathrm{~kg}(2.2-3.3 \mathrm{~kg} \pm 0.35)$. All animals recovered uneventfully. Temporal changes were examined by comparing data with baseline and control values. Total mean anaesthesia time was $116.17 \pm$ $43.72 \mathrm{~min}$ (range $80-210 \mathrm{~min}$ ) of which pneumoperitoneum was $67.89 \pm 18.89 \mathrm{~min}$ (56-119 $\mathrm{min}$ ). Premedication induced emesis in one cat. Rescue analgesia was necessary for 6 animals. Four animals required one bolus of $6 \%$ HES for hypotension correction (MAP $<60 \mathrm{mmHg}$ ).

The hemodynamic variables and body temperature (BT) are listed in Table 1 . There was no difference in MAP over the study. The heart rate (HR) showed an increase after the beginning of pneumoperitoneum $(\mathrm{P}<0.05$; Table 1), and the BT was lower at T2, T3 and T4 compared with baseline values.

Table 1. Values of physiologic parameters in cats during laparoscopy surgery

\begin{tabular}{lllll}
\hline \multirow{2}{*}{ Parameter } & $\begin{array}{l}\text { T1 } \\
\text { Mean } \pm \text { SD } \\
\text { (Range) }\end{array}$ & $\begin{array}{l}\text { T2 } \\
\text { Mean } \pm \text { SD } \\
\text { (Range) }\end{array}$ & $\begin{array}{l}\text { T3 } \\
\text { Mean } \pm \text { SD } \\
\text { (Range) }\end{array}$ & $\begin{array}{l}\text { T4 } \\
\text { Mean } \pm \text { SD } \\
\text { (Range) }\end{array}$ \\
\hline \multirow{2}{*}{ HR (bpm) } & $126 \pm 10.96$ & $\begin{array}{l}119.89 \pm 10.77 \\
(107-138)\end{array}$ & $\begin{array}{l}137.22 \pm 18.4 \\
(98-167)\end{array}$ & $\begin{array}{l}133 \pm 19.55 \\
(107-162)\end{array}$ \\
\hline \multirow{2}{*}{ RR (breaths) } & $22.78 \pm 10.96$ & $15.89 \pm 3$ & $17.4 \pm 2.22$ & $17.56 \pm 4.81$ \\
& $(13-34)$ & $(12-22)$ & $(14-20)$ & $(12-27)$ \\
\hline \multirow{2}{*}{ MAP (mmHg) } & - & $75.11 \pm 19.06$ & $82.33 \pm 12.65$ & $74.78 \pm 11.96$ \\
& & $(55-112)$ & $(65-110)$ & $(65-105)$ \\
\hline \multirow{2}{*}{ BT $\left({ }^{\circ} \mathrm{C}\right)$} & $38.56 \pm 0.54$ & $37.46 \pm 0.85$ & $36.96 \pm 0.24$ & $37.66 \pm 0.65$ \\
& $(37.6-39.3)$ & $(35.9-39)$ & $(36.5-37.2)$ & $(36.9-38.6)$ \\
\multirow{2}{*}{ SpO2 (\%) } & & $98.5 \pm 1.81$ & $98 \pm 1.06$ & $98.7 \pm 1.21$ \\
& & $(94-100)$ & $(97-100)$ & $(96-100)$ \\
\hline
\end{tabular}

$\mathrm{HR}$ indicates heart rate; $\mathrm{bpm}$, beats per minute; $\mathrm{RR}$, respiratory rate; $\mathrm{MAP}$, mean arterial pressure; $\mathrm{BT}$, body tempera-

ture; SpO2, oxygen saturation; $\mathrm{SD}$, standard deviation.

The results of mean $\mathrm{K}+$ concentration indicated a significant time effect, suggesting $\mathrm{K}+$ levels change in time. During the anaesthesia, $\mathrm{K}+$ increased from $3.75 \pm 0.56 \mathrm{mmol} / \mathrm{L}$ at $\mathrm{T} 1$ to $5.86 \pm 0.98 \mathrm{mmol} / \mathrm{L}$ at T4. Ionized magnesium concentration did not have a significant alteration, except at $\mathrm{T} 3$, which was considered higher than the value of T1. There were no significant changes in other electrolytes. Electrolyte trends with time are presented graphically in Fig.1. 
The $\mathrm{AB}$ values showed variations in pneumoperitoneum patients as regard to blood $\mathrm{pH}$ which was significantly lower at $\mathrm{T} 3(\mathrm{P}<0.05)$ compared with $\mathrm{T} 1$ and $\mathrm{T} 2$, increasing again by the end of surgery (Fig.2). $\mathrm{PvCO} 2$ and $\mathrm{PO} 2$ were almost two-fold increased at $\mathrm{T} 2$ and $\mathrm{T} 3$ as compared to $\mathrm{T} 1(\mathrm{P}<0.05)$, while in $\mathrm{T} 4$ their level exhibited a decreasing trend. Mean BE level registered a significant elevation after induction of anaesthesia $(\mathrm{P}<0.05)$, this trend persisting throughout the surgery. Negative correlations were registered between $\mathrm{pH}$ and $\mathrm{Na}(\mathrm{P}<0.05$; Pearson's coefficient -0.74$)$, iCa $(\mathrm{P}<0.001$, Pearson's coefficient -0.95$)$ and iMg $(\mathrm{P}<0.01$, Pearson's coefficient -0.86) at T3. There was no significant correlation between $\mathrm{PvCO} 2$ and $\mathrm{K}+$ or $\mathrm{pH}$ and $\mathrm{K}+$ in any time point during pneumoperitoneum. No correlation was identified between surgical time and $\mathrm{K}+$ level either.

As regard the blood glucose level, a significant increase occurred at $\mathrm{T} 2(\mathrm{p}<0.05)$, persisting beyond baseline values until the end of surgery (Fig.2).
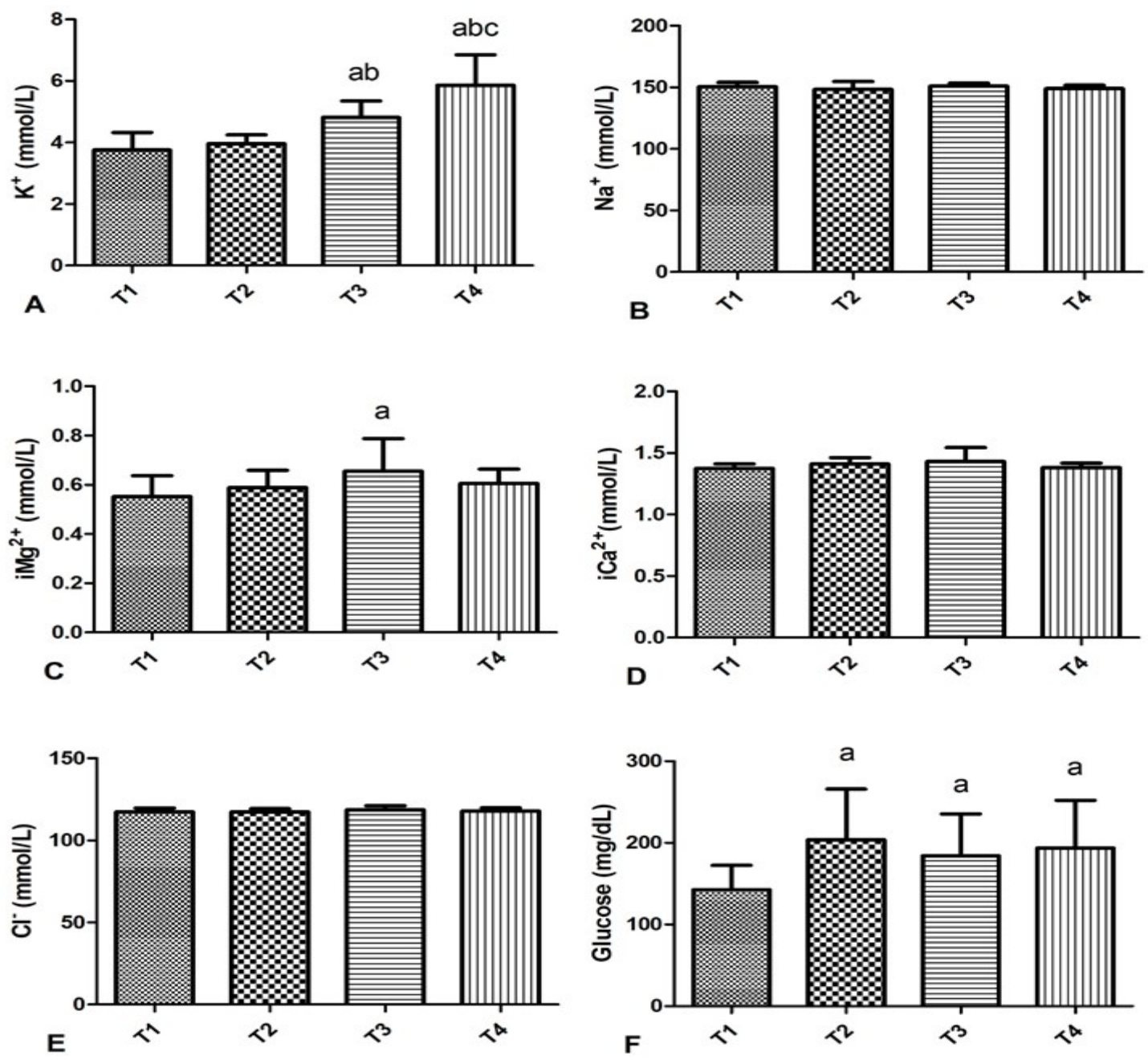

Figure 1. Effect of laparoscopic ovariectomy on blood electrolytes and glucose level. A - Potassium evolution, B - Sodium evolution, $\mathrm{C}$ - Ionised magnesium evolution, D - Ionised calcium evolution, E - Chloride evolution, F - Glucose evolution. (mean $\pm \mathrm{SD})(\mathrm{n}=9)(\mathrm{a}=\mathrm{p}<0.05$ as compared to T1) $(\mathrm{T} 1=$ Pre-induction, $\mathrm{T} 2=$ control, $\mathrm{T} 3=30$ min of pneumoperitoneum, $\mathrm{T} 4=$ the end of pneumoperitoneum) 

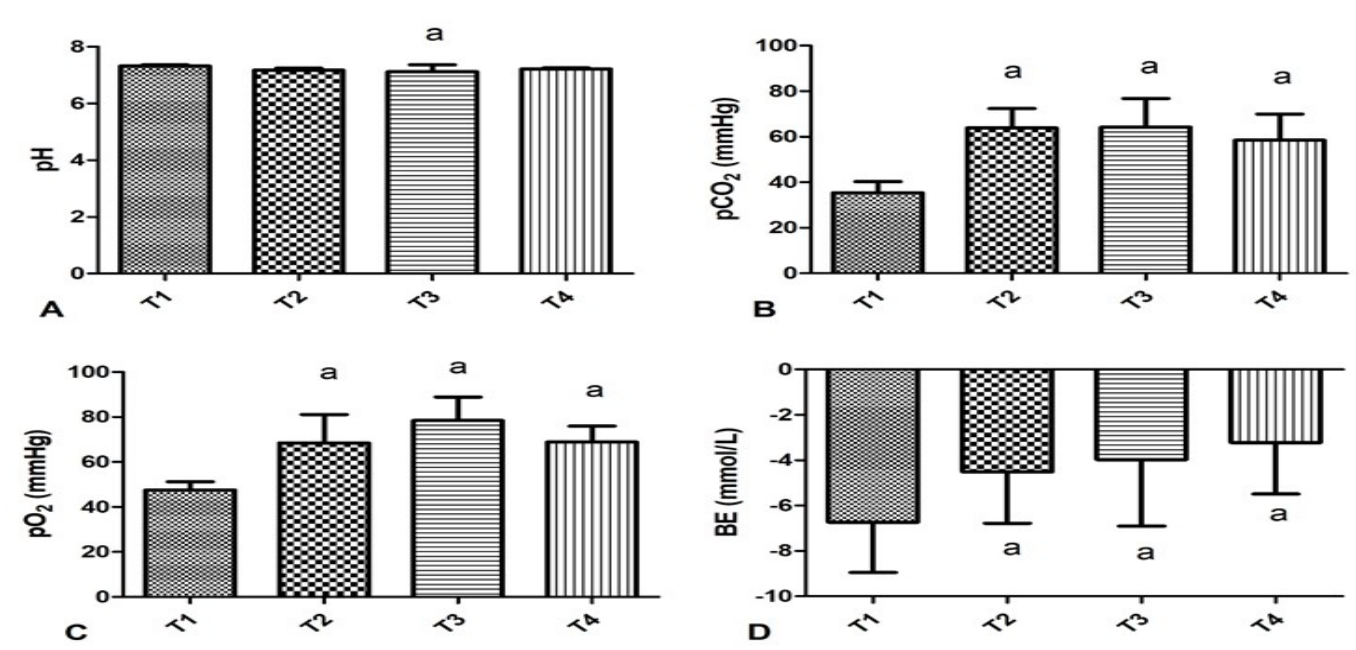

Figure 2. Effects of laparoscopic ovariectomy on blood $\mathrm{AB}$ values. $\mathrm{A}-\mathrm{pH}$ evolution, $\mathrm{B}-\mathrm{PvCO} 2$ evolution, $\mathrm{C}-\mathrm{PO} 2$ evolution, $\mathrm{D}-\mathrm{BE}$ evolution. (mean $\pm \mathrm{SD})(\mathrm{n}=9)(\mathrm{a}=\mathrm{p}<0.05$ as compared to $\mathrm{T} 1)(\mathrm{T} 1=$ Pre-induction, $\mathrm{T} 2=\mathrm{control}, \mathrm{T} 3=$ $30 \mathrm{~min}$ of pneumoperitoneum, $\mathrm{T} 4=$ the end of pneumoperitoneum)

\section{Discussion}

Pressure insufflation of $\mathrm{CO}_{2}$ inside the peritoneal cavity for laparoscopic surgery leads to undesirable conditions by causing modifications in respiratory, hemodynamic and AB balance [15]. In this study, changes in electrolytes in cats undergoing elective laparoscopic ovariectomy were evaluated. Our data suggests that some significant changes, although mostly transient, are evident. However, none of the changes of these parameters was of a magnitude likely to have clinical importance, at least not in healthy cats.

Blood analysis was performed from jugular blood collected by through venipuncture. Studies on feline $A B$ values reported significant differences between venous and arterial samples [28], showing that arterial blood is indispensable for evaluating $\mathrm{AB}$ status, oxygenations and ventilation, but not for electrolyte imbalances. The purpose of the present report was to analyse the evolution of selected electrolytes in anesthetized cats; therefore, venous blood was preferred over arterial.

The most important electrolyte modification observed was the progressive increase in $\mathrm{K}+$ concentration. These findings corroborate with those of previous studies evaluating the effect of $\mathrm{CO}_{2}$ peritoneal insufflation effect on $\mathrm{K}+$ homeostasis. Pearson et al. showed that following prolong insufflation of $\mathrm{CO}_{2}$ into the peritoneal cavity in pigs, the $\mathrm{K}+$ concentration increased over time [16]. Similar findings were registered by Demiroluk et al. and Singh et al. in human patients undergoing laparoscopic abdominal interventions [5] [24]. Likewise, Al-Badrany et al, in the experimental induced pneumoperitoneum study on dogs, showed a positive correlation between $\mathrm{K}+$ and abdominal pressure [1]. Reilly et al. while assessing biochemical and electrolyte alterations in captive tigers during laparoscopic ovariectomy, observed a similar increase over time in all animals, one tiger developing hyperkalaemia associated with ECG modifications [21]. The changes in potassium concentration in the current study were without clinical expression; nonetheless, these alterations might be relevant in critically ill feline patients at risk for hyperkalaemia. Concerning iCa concentration, the modifications partially corroborate findings from one previous study in dogs [1]. Ionized calcium concentration showed a tendency to increase in time, without a significant difference from baseline values. These results were contradictory with the study conducted by Reilly et al. on anaesthetized tigers in which the plasma calcium showed a significant decrease over the course of anaesthesia [21]. Likewise, Garg et al. related hypocalcaemia in a human patient during laparoscopic repair of a diaphragmatic hernia [10]. 
However, in their report, the iCa imbalance was attributed to fat tissue handling and necrosis, due to calcium binding to adipose tissue.

There were no changes registered in $\mathrm{Cl}^{-}$and Na+ concentrations in the present study. One study reported a change towards hyponatremia in dogs, but without significance, in response to hemodynamic instability [1]. As regard to iMg level, the findings were compatible with the study carried out by Kohler et al. in which was demonstrated that mobilization of magnesium from body tissues takes place if body $\mathrm{pH}$ is altered [14].

In our current investigation, the factors influencing the electrolyte balance varied during the anaesthesia. In the literature, modifications of blood $\mathrm{pH}$ and $\mathrm{PvCO}_{2}$ have been suggested as causes to induce electrolyte imbalances [7], [22]. After induction of anaesthesia, there was an increase in the mean $\mathrm{PvCO}_{2}$ concentration compared with baseline with significant value, attributable to anaesthesia drugs' specific respiratory depressive effects [11]. Once pneumoperitoneum started, there was a non-significant increase in the $\mathrm{PvCO}_{2}$. During laparoscopy, hypercarbia results from $\mathrm{CO}_{2}$ absorption through the peritoneal cavity into bloodstream and decreased alveolar ventilation [29]. As already demonstrated in previous studies, the increase in $\mathrm{PvCO}_{2}$ was negatively correlated with a decrease in blood $\mathrm{pH}$. Acidosis was a consistent finding during abdominal insufflation with $\mathrm{CO}_{2}$. If we compare the means of venous blood $\mathrm{pH}$ at pre-induction and during the surgery, there were significant differences during pneumoperitoneum. In response to the acute respiratory acidosis developed, there was a significant difference at BE levels relative to that at the pre-induction time, suggesting a respiratory factor as the cause of the decrease of $\mathrm{pH}$ during the surgical intervention.

Clinical studies sustain a linear relationship between hypercapnia and hyperkalaemia [12]. During acidosis, the movement of $\mathrm{K}+$ from intracellular space outwards occurs as a result of reduced $\mathrm{Na}+$, $\mathrm{K}+$-ATPase activity, with hydrogen entering in exchange of $\mathrm{K}+[7]$. Contrary to the aforementioned papers, the authors of this study could not identify any correlation between $\mathrm{pH}$ or $\mathrm{PvCO}_{2}$ evolution and hyperkalaemia. These findings coincided with the report of Weinberg et al. on human patients with experimental induced hypercapnia [31]. In this context, it could be suggested that the significant hyperkalaemia in this trial reflects a combination of the effects of extracellular $\mathrm{K}+$ shift due to acidosis and insulin deficiency and an assumptive decrease in renal perfusion. Administration of medetomidine in the present study caused a significant increase in glucose level in all patients, as a consequence of its mechanism of action by insulin inhibition [13]. Insulin deficiency plays an important role in the net efflux of $\mathrm{K}+$ from the cell, as frequently seen in diabetic patients [7]. In the study by Rilley et al. on electrolyte alterations in non-domestic felids, hypoinsulinemia coincided with hyperglycaemia and induced clinically important hyperkalaemia in one anesthetised tiger. This finding was in accordance with our results; however, hyperkalaemia has been shown to be a complication frequently associated with administration of alpha 2 adrenergic agonists in large felids [26]. Kidneys play an esential role in $\mathrm{AB}$ and electrolyte balance. Temporary reversible oliguria during pneumoperitoneum has been observed in clinical and experimental studies as a consequence of low renal perfusion [19]. This side effect could have been associated to a diminished K+ excretion; however, in our study, urine output was not monitored.

Pearson and Sander, in their experimental study performed in pigs, concluded that long duration pneumoperitoneum can lead to clinically important hyperkalemia [16]. In our study, the average time of pneumoperitoneum was $68 \mathrm{~min}$, with a wide range of 56 and $119 \mathrm{~min}$. There was a significant increase in $\mathrm{K}+$ value at a peritoneal pressure maintained stable at $8 \mathrm{mmHg}$, although no relationship between the time of pneumoperitoneum and potassium concentration was found.

On the other hand, the iCa and iMg evolution were negatively correlated with $\mathrm{pH}$ evolution. Both calcium and magnesium can be found in circulation in different fractions, from which the ionized form usually reflects the true status in case of $\mathrm{AB}$ disturbances [2] [23]. Clinical and laboratory researches have already demonstrated the $\mathrm{pH}$ influence on iCa concentration, suggesting a magnitude of $0.05 \mathrm{mmol} / \mathrm{L}$ for every 0.1 $\mathrm{pH}$ change [17]. Similarly, in the study by Wang et al. (2002), $\mathrm{pH}$ proved to have a direct effect on magnesium measurement, as a result of a weak binding to plasma protein in a more acidic environment [30]. In the current study, this relationship was highlighted by the patient with severe respiratory acidosis seen at min 30 of pneumoperitoneum, in which iCa reached the highest value $(1.72 \mathrm{mmol} / \mathrm{L})$, at a level considered in 
veterinary medicine as severe hypercalcemia [4], associated with a concomitant increment of iMg $(0.98$ $\mathrm{mmol} / \mathrm{L}$ ). The authors attributed this imbalance to improper ventilation, BG and electrolyte analysis improving after ventilator settings were modified.

A negative correlation was recognized at $\mathrm{T} 2$ between $\mathrm{Cl}^{-}$and Na+ concentration. The correlation was changed during pneumoperitoneum, the variables moving together in a positive direction. These findings could be attributable to a renal and gastrointestinal response to acute respiratory acidosis. Ramadoss et al. demonstrated the renal response manifested through $\mathrm{Cl}^{-}$excretion with respect to $\mathrm{Na}+$ within 30 minutes of acute respiratory acidosis [18]. As a further compensation mechanism, as suggested by Feldman and Charney, gastrointestinal reabsorption of both electrolytes is initiated [9]. Nevertheless, additional research is needed to support this supposition.

There are limitations in our study. First, there were no assessments performed after recovery from anesthesia. In addition, a small number of animals was involved in the study and the absence of a control group. The use of control group undergoing open laparotomy procedure would have been of interest in comparatively monitoring electrolyte disturbances. Moreover, it would be recommended to further evaluate these findings with different anaesthesia protocols.

In summary, the present study demonstrates a significant rise in $\mathrm{K}+$ and $\mathrm{iMg}$ concentrations, not sufficient enough to cause clinical expression, in healthy cats undergoing elective laparoscopic ovariectomy. These changes occurred partially as a consequence of decreased blood $\mathrm{pH}$ and hypercarbia, and were associated with general anaesthesia, $\mathrm{CO}_{2}$ gas diffusion and increased intraperitoneal pressure. However, further studies should investigate other possible causes of $\mathrm{K}+$ concentration increase, as this parameter had the most significant alterations. The possibility of hyperkalemia has to be considered in all patients undergoing laparoscopic surgery, possessing a real challenge to anaesthetists. Therefore, monitoring of electrolytes may be important for increased safety during laparoscopic surgeries, particularly in patients with risk factors.

Author Contributions: IM, CP, LB and CAD initiated the study and designed the experiments. IM and MD contributed with data collection. Data management was done by IM, CP and SB. Data analyses and preparation of was done primarily by SB, with contributions from IM. IM, CP and LB drafted the manuscript. LO critically revised the manuscript. All authors have read and agreed to the published version of the manuscript.

Funding: This research received no external funding.

Conflicts of Interest: The authors declare no conflict of interest.

\section{References}

1. Al-Badrany, M.S., Kalo, M.S., Al-Anaaz M.T. Hematological and gas analyzer with acid base balance of pneumoperitoneum in dogs exposed to laparoscopy. IJERSTE 2014, 3, 90-96.

2. Bateman S.: Disorders of Magnesium: Magnesium Deficit and Excess. In: Fluid, electrolyte and acid-base disorders in small animal practice, $4^{\text {th }}$ ed.; DiBartola S.P. Eds; Saunders, Philadelphia, USA, 2006, pp. 212.

3. Buote N.J.: Laparoscopic ovariectomy and ovariohysterectomy. In: Small animal laparoscopy and thoracoscopy, $1^{\text {st }}$ ed.; Fransson, B.A., Mayhwe, P.A., Wiley Blackwell, Iowa 2015, pp. 207.

4. Coady, M., Fletcher, D.J., Goggs, R. Severity of ionized hypercalcemia and hypocalcemia is associated with etiology in dogs and cats, Front Vet Sci, 2019, 6, pp. 276.

5. Demiroluk, S., Salihoglu, Z., Bozkurt, P., Hayirlioglu, M., Mose, M.: Effect of pneumoperitoneum on the level of plasma potassium. Middle East J Anaesthesiol 2007, 19, 61-70.

6. DiBartola, S.P.: Introduction to acid-base disorders. In: Fluid, electrolyte and acid-base disorders in small animal practice, $4^{\text {th }}$ ed.; DiBartola S.P. Eds, Saunders, Missouri, USA, 2012, pp. 231-252.

7. DiBartola S.P., de Morais H.A.: Disorders of potassium: hypokalemia and hyperkalemia. In: Fluid, electrolyte, and acid-base disorders in small animal practice, $4^{\text {th }}$ ed.; DiBartola S.P. Eds., Saunders, Missouri, USA, 2012, pp. 92-119.

8. Dupre G.: Laparoscopic access techniques. In: Small animal laparoscopy and thoracoscopy, $1^{\text {st }}$ ed.; Fransson B.A., Mayhew P.A. Eds., Wiley Blackwell, Iowa, USA, 2015, pp. 81-86. 
9. Feldman G.M. and Charney A.N.: Effect of acute respiratory alkalosis and acidosis on intestinal ion transport in vivo. Amer J of Physiol 1982, 242, pp. 486-489.

10. Garg, R., Punj, J., Pandey, J., Darlong, V. Delayed recovery due to exaggerated acid, base and electrolyte imbalance in prolonged laparoscopic repair of diaphragmatic hernia. Saudi J Anaesth. 2011, 5, pp. 79-81.

11. Golden, A.L., Bright, J.M., Daniel, G.B. Cardiovascular effects of the $\alpha 2$-adrenergic receptor agonist medetomidine in clinically normal cats anesthetized with isoflurane. AJVR; 1998, 59, pp. 509-513.

12. Hassan H., Gjessing J., Tomlin J.: Hypercapnia and Hyperkalaemia; Anaesthesia, 1979, 34, pp. 897-889.

13. Kanda T., Hikasa, Y.: Neurohormonal and metabolic effects of medetomidine compared with xylazine in healthy cats; Can J Vet Res 2008, 72, pp. 278-286.

14. Kohler, E., Noack, E., Strobach, H., Wirth K. Effect of respiratory acidosis on heart and circulation in cats, pigs, dogs and rabbits; Res Exp Med (Berlin) 1972, 158, pp. 308-320.

15. Mama K., de Rezende L.M.: Anesthesia management of dogs and cats for laparoscopy. In: Small animal laparoscopy and thoracoscopy, $1^{\text {st }}$ ed.; Fransson B.A., Mayhew P.A. Eds., Wiley Blackwell, Iowa, USA, 2015, pp. 75-79.

16. Pearson M.R., Sander M.L.: Hyperkalaemia associated with prolonged insufflation of carbon dioxide into the peritoneal cavity. Br J Anaesth 1994, 72, pp. 602-4.

17. Rajini, T.S., Prudhvi, K., Kumar, P.N., Sravani, N.S., Tejaswi, N., Alekya, B., Govardhini, B., Rajagopalan, B.: Assessment of Ionized Calcium Levels in Various Acid Base Disorders in ICU Patients. Int J Pharm Sci Rev Res 2018, 49, pp. 60-64.

18. Ramadoss J., Stewart R.H., Cudd T.A.: Acute Renal Response to Rapid Onset Respiratory Acidosis. Can J Physiol Pharmacol 2012, 89, pp. 227-231.

19. Razvi, H.A., Fields, D., Vargas, J.C., Vaughan Jr. E.D., Vukasin A., Sosa R.E. Oliguria during laparoscopic surgery: evidence for direct renal parenchymal compression as an etiologic factor. J Endourol 1996, 10, pp. 1-4.

20. Reddi, A.S.: Respiratory acidosis. In: Fluid, electrolyte and acid-base disorders, Clinical evaluation and management, $1^{\text {st }}$ ed.; Reddi A.S., Springer, New York USA, 2014, pp. 410-412.

21. Reilly S., Seddighi M.R., Steeil J.C., Sura P., Whittemore J.C., Gompf R.E., Ramsay E.C.: Selected clinical, biochemical, and electrolyte alterations in anesthetized captive tigers (panthera tigris) and lions (panthera leo). J Zoo Wildl Med 2014, 45, pp. 328-334.

22. Robinson, N.E. Acid-base homeostasis. In: Cunningham's textbook of veterinary physiology, $5^{\text {th }}$ ed.; Klein B.G., Saunders, Virginia, USA, 2013, pp. 549.

23. Schenck, P.A., Chew, D.J., Nagode, L.A., Rosol, T.J.: Disorders of Calcium: Hypercalcemia and Hypocalcemia In: Fluid, electrolyte and acid-base disorders in small animal practice, $4^{\text {th }}$ ed.; DiBartola S.P., Saunders, Missouri, USA, 2006, pp. 121.

24. Singh, J., Singha, D., Verma, R.K., Sodhi, S.S., Bhandari, S., Thakur, A.: Estimation of Serum Potassium in Patients Undergoing Laparoscopic Cholecystectomy. AIMDR 2016, 2, pp. 15-20.

25. Shih, A.C., Case J.C., Coisman, J.G., Isaza, N.M., Amora-Junior, D., Maisenbacher, H.B.: Cardiopulmonary Effects of Laparoscopic Ovariectomy of Variable Duration in Cats. Vet Surg 2015, 44, pp. 2-6.

26. Steeil J., Ramsay E.C., Schumacher J., Marin M., Mosley C., Reilly S., Seddighi M.R.: Hyperkalemia in exotic felids anesthetized with an alpha - 2 adrenoceptor agonist, ketamine, and isoflurane. Proceedings Annual Conference AAZ 2013.

27. Sümpelmann, R., Schuerholz, T., Marx, G., Härtel, D., Hecker, H., Ure, BM., Jesch, M.K.: Haemodynamic, acid-base and blood volume changes during prolonged low pressure pneumoperitoneum in rabbits. Br J Anaesth., 2006, 96, pp. 563-568.

28. Tamura, J., Itami, T., Ishizuka, T., Fukui, S., Miyoshi, K., Sano, T., Yamashita, K. Central venous blood gas and acid-base status in conscious dogs and cats. J Vet Med Sci, 2015, 77, pp. 865-869.

29. Veekash, G., Wei, L.X., Su, M. Carbon dioxide pneumoperitoneum, physiologic changes and anesthetic concerns, Ambulatory Surgery 2010, 16, pp. 41-46.

30. Wang, S., McDonnell, E., Sedor, F.A., Toffaletti, J.G.: pH Effects on measurements of ionized calcium and ionized magnesium in blood. Arch Pathol Lab Med 2002, 126, pp. 947-950.

31. Weinberg, L., Russell, A., Mackley, L., Dunnachie, C., Meyerov, J., Tan, C., Li M., Hu, R., Karalapillai, D. Relationship between acute hypercarbia and hyperkalaemia during surgery. World J Clin Cases 2019, 7, pp. 3711-3717. 